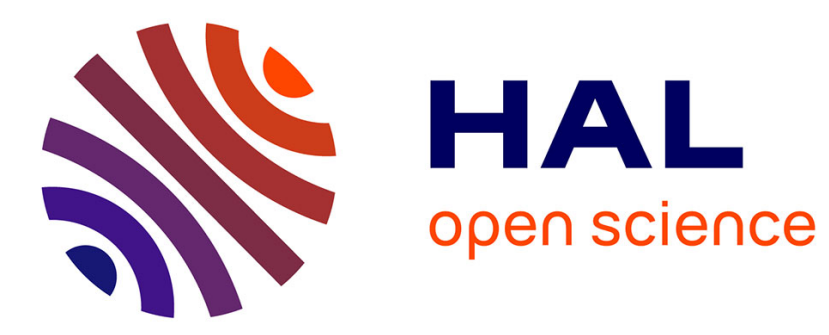

\title{
Improved Performance of Hybrid Photovoltaic-Trigeneration Systems Over Photovoltaic-Cogen Systems Including Effects of Battery Storage
}

Amir Nosrat, Lukas Swan, Joshua Pearce

\section{To cite this version:}

Amir Nosrat, Lukas Swan, Joshua Pearce. Improved Performance of Hybrid PhotovoltaicTrigeneration Systems Over Photovoltaic-Cogen Systems Including Effects of Battery Storage. Energy, 2013, 49, pp.366-374. 10.1016/j.energy.2012.11.005 . hal-00769200

\section{HAL Id: hal-00769200 \\ https://hal.science/hal-00769200}

Submitted on 29 Dec 2012

HAL is a multi-disciplinary open access archive for the deposit and dissemination of scientific research documents, whether they are published or not. The documents may come from teaching and research institutions in France or abroad, or from public or private research centers.
L'archive ouverte pluridisciplinaire HAL, est destinée au dépôt et à la diffusion de documents scientifiques de niveau recherche, publiés ou non, émanant des établissements d'enseignement et de recherche français ou étrangers, des laboratoires publics ou privés. 
Preprint of: A.H. Nosrat, L.G. Swan, J.M. Pearce, Improved Performance of Hybrid Photovoltaic-Trigeneration Systems Over Photovoltaic-Cogen Systems Including Effects of Battery Storage, Energy 49, pp. 366-374 (2013). http://dx.doi.org/10.1016/j.energy.2012.11.005

\title{
Improved Performance of Hybrid Photovoltaic-Trigeneration Systems Over Photovoltaic-Cogen Systems Including Effects of Battery Storage
}

\author{
Amir H. Nosrat ${ }^{1}$, Lukas G. Swan ${ }^{2}$, and Joshua M. Pearce ${ }^{3 *}$ \\ 'Department of Mechanical and Materials Engineering, Queen's University, 60 Union Street \\ Kingston, Ontario, K7L 3N6 Canada (amir.nosrat@queensu.ca) \\ ${ }^{2}$ Department of Mechanical Engineering, Dalhousie University, 1360 Barrington St. Halifax, Nova Scotia, \\ Canada, B3J 1 Z1 (Lukas.Swan@dal.ca) \\ ${ }^{3}$ Department of Materials Science \& Engineering and Department of Electrical \& Computer Engineering, \\ Michigan Technological University, 601 M\&M Building, 1400 Townsend Drive \\ Houghton, MI 49931-1295 (pearce@ mtu.edu)
}

*Corresponding author: pearce@mtu.edu ph: 906-487-1466

\begin{abstract}
Recent work has proposed that hybridization of residential-scale cogeneration with roof-mounted solar photovoltaic (PV) arrays can increase the PV penetration level in ideal situations by a factor of five. In regions where there is a significant cooling load PV-cogen hybrid systems could be coupled to an absorption chiller to utilize waste heat from the cogen unit. In order to investigate realistic (non-ideal) loads that such a hybrid system would need to service, a new numerical simulation called PV-Trigeneration Optimization Model (PVTOM) was created and coupled to the results of the established Canadian Hybrid Residential End-Use Energy and Emissions Model (CHREM). In this paper, PVTOM is applied to representative houses in select Canadian regions, which experience cooling loads, to assess the fuel utilization efficiency and reduction in greenhouse gas emissions from hybrid PV cogen and trigen systems in comparison with conventional systems. Results of the optimization runs are provided and the efficacy of PV-cogen and PV-trigen systems are discussed. Both PVtrigen and PV-cogen systems have demonstrated to be more effective at reducing emissions when compared to the current combination of centralized power plants and household heating technologies in some regions.
\end{abstract}

Keywords: cogeneration; greenhouse gas emissions; photovoltaic; trigeneration; combined heat and power; solar energy

\section{Introduction}

Anthropogenic climate destabilization caused by human induced greenhouse gas (GHG) emissions has the potential to upset human welfare, global ecosystems, and the temperate climate in which most people live.

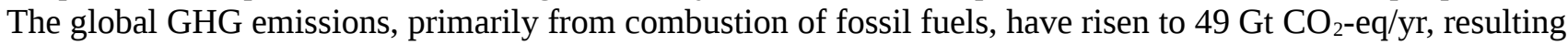
in an increase in atmospheric carbon concentration from a pre-anthropocene level of $280 \mathrm{ppmv}$ to over 380 ppmv today [1]. Numerous climate change scientists now recommend that in order to avoid disruption to the climate and negative effects on human society, GHG emissions should be stabilized at levels below $350 \mathrm{ppmv}$ [2]. Electricity represents approximately $17 \%$ of worldwide secondary energy consumption, the majority of which (approximately 68\%) is generated by primary energy from fossil fuels [3]. Consequently, electricity generation is a significant contributor to GHG emissions. Average conversion efficiency from fossil fuels to electricity in Unites States power plants is 33\% for coal-fired and 43\% for natural gas-fired based on higher heating values [4], resulting in the majority of the chemical energy becoming waste heat.

There are two clear strategies to reduce present GHG emission rates from electrical energy sources: (1) use fossil fuels more effectively and efficiently, ${ }^{1}$ and (2) use sustainable and renewable energy, which does not

1 It should be noted here that this strategy may be reductionist as it does not account for impacts on consumer behavior as a result of increased efficiency in fuel consumption. 
Preprint of: A.H. Nosrat, L.G. Swan, J.M. Pearce, Improved Performance of Hybrid Photovoltaic-Trigeneration Systems Over Photovoltaic-Cogen Systems Including Effects of Battery Storage, Energy 49, pp. 366-374 (2013). http://dx.doi.org/10.1016/j.energy.2012.11.005

directly emit GHGs during energy conversion and which also tends to have low embodied and dynamic emissions [5]. With consideration to the generation of electricity using strategy (1), an obvious method of increasing fossil fuel utilization efficiency is to divert the "waste heat" to applications that require low-grade thermal energy, a hybrid method termed cogeneration (cogen) or combined heat and power (CHP) [6]. Examples of low-grade thermal energy applications include space heating, domestic and process hot water, and lowpressure steam. With the addition of an absorption chiller, space cooling can be achieved in so called trigeneration (trigen) or combined cooling, heat and power (CCHP) [7-9]. The simultaneous generation of electricity and low-grade heat to meet multiple applications has several advantages over conventional electricity generation systems. These advantages include i) decreased primary energy consumption in comparison with separate electricity/heat systems, ii) reduced transmission and distribution losses by generating electricity on-site or near the end-use requiring heat, and iii) decreased need to establish new power plants by meeting the needs of certain end-uses with low-grade heat as opposed to electricity. The term on-site refers to systems that are in extreme geographic proximity, even within, a consumer's property.

With consideration to the generation of electricity and strategy (2), the utilization of solar photovoltaic (PV) technology, which directly converts sunlight into electricity, has been proposed as a sustainable solution [10-13]. However, PV technologies are limited by the solar resource, particularly the intermittency of solar insolation owing to the daily solar cycle and cloudy weather conditions. Recent work has shown that PV and CHP technologies have complementary attributes including reduced CHP capacity size and GHG emissions and increased electrical output reliability to make up for the inherent intermittency of PV [14-16]. In particular, the electrical grid penetration level of PV, defined as the ratio of PV-generated electricity to the total electricity provided at the electrical grid, can be increased up to $25 \%$ with the use of small household scale hybrid PV+CHP systems [14]. The addition of battery energy storage, which stores and releases electricity, to a PV+CHP system can allow for increased utilization of the PV and CHP components by de-coupling the electrical and thermal energy generation and loads. However, questions remain about the effectiveness of PV+CHP systems including the fuel utilization efficiency of the CHP component, and the ability of such PV+CHP systems to reduce GHG emissions in comparison with separate electricity and thermal energy systems which may be supplied from a variety of energy sources. Furthermore, the potential of PV+CCHP systems (i.e. the inclusion of cooling) has not yet been investigated in great detail.

In this article CHP, PV, battery energy storage, and CCHP are briefly reviewed. A new numerical simulation titled PV-Trigeneration Optimization Model (PVTOM) is then presented. PVTOM employs multiobjective genetic algorithms to select $\mathrm{PV}+\mathrm{CHP}$ or $\mathrm{PV}+\mathrm{CCHP}$, and battery energy storage systems that minimize both life cycle costs (LCC) and GHG emissions based on the specific application. The PVTOM method is applicable in any geographic location, however to elucidate its use, it is demonstrated here by coupling it to the discrete electricity and heat load profiles of Canadian houses obtained from the Canadian Hybrid Residential End-Use Energy and Emissions Model (CHREM) [17-19]. The PVTOM results are then used assess the fuel utilization efficiency and reduction in GHG emissions in comparison with conventional systems. These results are discussed in detail and the positive and negative findings of PV+CHP and PV+CCHP systems are summarized.

\section{Background}

Hybrid systems such as PV+CCHP rely on several advanced technologies including renewable and alternative energy conversion devices, and electricity energy storage. This section briefly introduces these technologies, and reviews recent status and advances in their performance and scale. The technologies are introduced in a specific order to show how they complement one another by addressing specific limitations and deficiencies.

\subsection{Review of CHP}

A typical coal-fired power plant used for generation of electricity achieves fuel utilization efficiency of $33 \%$ based on the electricity produced and the fossil fuel higher heating value; the remaining low-grade heat is exhausted to the environment [4]. Fuel utilization efficiency, defined as the ratio of useful work (electricity) and 
Preprint of: A.H. Nosrat, L.G. Swan, J.M. Pearce, Improved Performance of Hybrid Photovoltaic-Trigeneration Systems Over Photovoltaic-Cogen Systems Including Effects of Battery Storage, Energy 49, pp. 366-374 (2013). http://dx.doi.org/10.1016/j.energy.2012.11.005

heat output to fossil fuel higher heating value, can be increased significantly by generating the electricity at the site where it is used ("on-site"), and taking advantage of the low grade exhaust heat. Although an effect of this CHP system is a slight decrease in electrical generation efficiency, this loss is offset by considerably higher quantities of low-grade heat being delivered to suitable applications [6]. Because of recent advances in CHP technology, systems may be scaled to nearly any size (watts to megawatts, electrical and thermal).

In a CHP system a prime mover such as an engine or turbine, or a more recent alternative such as a fuel cell, is responsible for converting fuel into electricity. As a result of fossil fuel use, CHP units do emit GHGs. The maximum practical fuel utilization efficiency for conversion to electricity is approximately $50 \%$, and thus nearly half of the fuel energy is exhausted as waste heat [6]. By using heat exchangers, this heat can be diverted as a low temperature fluid for suitable applications. Utilizing both electrical and thermal outputs, fuel utilization efficiency higher than $85 \%$ can be achieved $[6,20]$. The total fuel utilization efficiency ${ }^{2}$ for a CHP system is given by:

$$
\eta_{C H P}=\frac{Q_{C H P}+W_{C H P}}{Q_{O}}
$$

where $Q_{\text {СнP }}$ and $\mathrm{W}_{\mathrm{CHP}}$ represent utilized thermal and electrical energy, respectively, and $Q_{o}$ represents the higher heating value of the consumed fuel. The electricity $\mathrm{W}_{\text {Снр }}$ is used either on-site or fed into the electricity grid. The delivered heat $Q_{\text {СнР }}$ must have an acceptable quality, quantity, and temperature to meet the thermal needs of the application.

The thermal needs of the application often govern the fuel utilization efficiency of the CHP system, and limit its applicability and economic feasibility. A typical CHP system produces thermal output equal to three times electrical output [6]. As an example of applicability, consider the thermal and electrical requirements of a typical house in Kingston, Ontario, Canada, as shown in Figure 1 which was created from information obtained from the CHREM. In the Canadian climate, space heating (thermal) dominates energy requirements but varies considerably throughout the year, as does the more minor space cooling (thermal). In contrast, the domestic hot water (thermal) and appliances and lighting (electricity) requirements are nearly constant. As a result, the ratio of thermal to electrical requirement varies from 1.3 to 6.6. From November through April, the ratio is greater than three, indicating a CHP unit would meet the electricity requirements of the house and contribute to the thermal requirements, the balance being obtained by an auxiliary system. As an alternative, the CHP unit could meet the thermal requirement from November through April, meanwhile exporting electricity to the grid. During summer months of May through October one of the two following non-optimal conditions would occur: i) there would be either excess thermal energy generated by the CHP unit as it supports the entire electricity requirement, or ii) additional electricity is required from the grid as the CHP unit limits output to the thermal requirement.

Obviously other locations or applications will have different energy requirement characteristics; however, the summertime condition shown in Figure 1 where a CHP is non-optimal is consistent for residential and commercial sectors in temperate climates. As such these periods offer opportunity for additional technologies to complement the CHP unit.

\subsection{Review of Photovoltaic Technology}

\section{Figure 1}

PV technology directly converts sunlight into electricity at commercial conversion efficiencies ranging from $6-20 \%$. As it relies on a renewable energy source, the technology does not emit GHGs. PV technology has become economically viable in a number of applications and geographic regions due to advancements in manufacturing processes, and has become attractive under various government economic frameworks such as Germany and Ontario Canada, and as a result, the installed capacity has recently been growing at a rate of $40 \%$ $[3,21-24]$.

2 From a technical perspective, exergy is a better determinant of system performance. The goal of PVTOM, however, is to encapsulate economic decision-making, which has a more direct link with fuel utilization than changes in exergy. 
Preprint of: A.H. Nosrat, L.G. Swan, J.M. Pearce, Improved Performance of Hybrid Photovoltaic-Trigeneration Systems Over Photovoltaic-Cogen Systems Including Effects of Battery Storage, Energy 49, pp. 366-374 (2013). http://dx.doi.org/10.1016/j.energy.2012.11.005

PV technology relies on solar insolation as its energy source, operating only during the daytime and being affected by seasonal and local weather conditions such as clouds. For example, consider the seasonal and daily direct solar radiation for Kingston, Ontario, Canada, as shown in Figure 2. Figure 2(a) shows both the direct and diffuse radiation throughout the year. Depending on the type of photovoltaic device the diffuse radiation will provide additional power. However, it is clear that PV technology is not consistent throughout the year and will generate the most electricity during summer months regardless of the photovoltaic material. By comparing the PV electricity generation characteristics with the ratio of thermal to electrical requirements as seen in Figure 1 and has been done for the U.S. [14], it is apparent that PV technology may be combined with a CHP unit to produce sufficient electricity to meet the application without overproducing thermal energy.

Figure 2.

Figure 2 (b) shows a representative sunny solar day in mid-summer. Variation due to daytime hours as well as clouds is readily apparent in both the direct and the diffuse radiation. This can be overcome in a hybrid system utilizing a battery energy storage system [15]. Because of its intermittency and frequent mismatch between production and load, the coupling of PV with electricity production technologies, which are able to be dispatched, such as CHP systems can potentially have significant positive impacts on increasing utilization and PV penetration levels [14]. On solar intense days it is possible to generate more electricity with the PV than load of the application. Consequently, electricity must be either exported to the electrical grid or, as an alternative, the use of battery energy storage [25].

\subsection{Review of Battery Energy Storage Technology}

Batteries are electricity storage devices that rely on electro-chemical processes to store energy in chemical form. In a hybrid system, excess energy from either the CHP unit or the PV array can be stored in a battery. Most hybrid systems utilize deep-cycle lead-acid types, or more recently lithium-ion. It should be noted that energy storage devices in general provide a major obstacle in technical, environmental, and economic realms and can have negative environmental impacts if not disposed of properly. However, there are no readily available alternatives to store energy excesses in small scale hybrid systems. In technical terms, the lead-acid battery storage is subject to relatively strenuous operating conditions such as undercharging, overcharging and remaining in a low state of charge of prolonged periods of time [26]. In most hybrid system lifetimes (20+ years), the batteries require replacement (4 to 15 years) can have a significant impact of the lifetime cycle cost of the system.

The battery storage capacity is given in amp-hours and in some instances in $\mathrm{kWh}$ (the product of the amp-hours and the nominal battery voltage). In general, power capability and energy storage capacity is dependent on the cycling conditions, battery type/size/age, and management methods.

\subsection{The combination of CHP, PV, absorption chilling and battery energy storage technology}

Figure 3 illustrates the energy flow of a hybrid PV and cogen system where there are two primary sources of energy: i) solar radiation and ii) fuel for the cogeneration unit. Electricity generated by the PV array and the cogeneration unit are used to meet the electric load, which in most cases is connected to a grid. Excess electricity is stored in the battery and utilized during times where the PV array and cogeneration unit fail to meet the demand. Any electricity that is not produced by the combination of PV, CHP, and the battery are provided by the grid.

The cogeneration unit also produces thermal energy, which is harnessed by a heat exchanger and utilized to provide space heating and domestic hot water in the case of a PV+CHP system.

Figure 3.

To overcome a fundamental CHP limitation, a cooling process may be introduced to use waste heat during the cooling season by incorporating an absorption chiller, creating a trigeneration system with cooling capabilities (as seen in the bottom sub-box of Figure 3). The regeneration of the absorption cooling technologies is provided 
Preprint of: A.H. Nosrat, L.G. Swan, J.M. Pearce, Improved Performance of Hybrid Photovoltaic-Trigeneration Systems Over Photovoltaic-Cogen Systems Including Effects of Battery Storage, Energy 49, pp. 366-374 (2013). http://dx.doi.org/10.1016/j.energy.2012.11.005

by the thermal energy of the original cogen system. These systems are referred to as hybrid PV and trigeneration or PV-CCHP.

Both hybrid system types utilize the same primary sources of energy. Therefore, energy utilized by the system for space cooling, especially in warmer seasons, has the potential of increasing the energy utilization efficiency and further reducing GHG emissions.

\section{Methodology}

A numerical simulation and optimization of residential-scale PV-Trigen systems called PV-Trigeneration Optimization Model (PVTOM) has been developed to provide a comparison of energy utilization efficiency for PV-trigen and PV-cogen systems [29]. PVTOM incorporates multi-objective genetic algorithms to minimize both life cycle costs (LCC) and GHG emissions. The LCC include the capital investment, fuel costs, and replacement costs over a 20 year system lifetime. Disposal costs are only considered for the batteries, which are marginal. The GHG emissions are calculated as the carbon dioxide equivalent of the CHP unit's total emission (determined as a function of energy output) as well as any emissions produced as a result of relying on the electric grid or heating furnaces. The hybrid system only emits GHG emissions from the CHP unit which operates from natural gas, diesel, biodiesel, a fuel cell, or other alternative fuel sources. Presently, PVTOM uses the annual average GHG emission intensity of the local electricity grid. Future versions of PVTOM are intended to incorporate transmission losses and hourly emission intensities for different grids.

\section{Figure 4.}

The PVTOM optimization algorithm is presented in Figure 4. Hourly raw horizontal solar radiation and temperature data from the METEO database is accessed through PVSyst 4.37. ${ }^{3}$ The raw horizontal radiation data is converted into direct beam radiation for the optimal tilt angle of a given location that is necessary to simulate the PV panels' performance. PVTOM requires the four major residential end use energy requirements at a 1-hour resolution:

1. Appliances and lighting (AL)

2. Domestic hot water (DHW)

3. Space heating (SH)

4. Space cooling (SC)

The end-user energy requirements can either be obtained from historical data or representative data calculated from the Canadian Hybrid Residential End-use Energy and Emissions Model (CHREM). The CHREM [17-19] is capable of assessing the energy demand of the four major end-use groups of the Canadian housing stock. Key features of the CHREM that enable this predictive capability are:

- The use of a statistically representative database of 16,952 unique Canadian house descriptions that include thermal envelope and plant system information. The database contains a sufficient number of unique houses to capture the range of housing characteristics found throughout Canada. Additionally, the database provides sufficient information to develop detailed thermal and electrical energy models of each unique house.

- The use of a unique "hybrid" modeling approach that relies on both statistical and engineering bottomup modeling methods. The statistical component is used by CHREM to assess the AL and DHW energy consumption including the impacts of occupant behavior. The engineering component is used by CHREM to assess the SH and SC energy consumption based on thermodynamic and heat transfer analysis of the thermal envelope, climatic conditions, and plant equipment.

- The ability to assess impacts upon end-use energy consumption due to the implementation of advanced, alternative, and renewable energy technologies using the engineering component at an hourly or sub-

\footnotetext{
3 http://www.pvsyst.com/
} 
Preprint of: A.H. Nosrat, L.G. Swan, J.M. Pearce, Improved Performance of Hybrid Photovoltaic-Trigeneration Systems Over Photovoltaic-Cogen Systems Including Effects of Battery Storage, Energy 49, pp. 366-374 (2013). http://dx.doi.org/10.1016/j.energy.2012.11.005

hourly simulation time step.

A simplified flowchart of the CHREM is presented in Figure 5.

Figure 5.

PVTOM optimizes the objective functions based on the seven following variables:

1. PV technology selection

2. CHP technology selection

3. Battery technology selection

4. Number of PV strings in parallel (the number of PV panels in one series string is equal to the size of the system voltage divided by the PV voltage rating)

5. Number of batteries in parallel

6. Number of parallel batteries in series

7. Number of CHP systems in parallel (included CHP units are designed to operate at end-user household voltages)

In GA, the objective function is dubbed as the fitness function, which will determine the advantage or disadvantage of a particular string of variables compared to the remainder of the population. The objective function is the final determinant of the system's performance based on the user's interests and goals. In the model, there are two competing objective functions that cannot be quantified in similar manners: life cycle costs and emissions. While there has been scholarly work on the quantification of emissions in monetary values, these are heavily dependent upon model assumptions, geographic location, as well as legal and economic frameworks that can vary from city to city. The present purpose of the hybrid optimization model is not to be constrained to specific applications, though such specifications could certainly be worked in any future adaptations of the model.

The two fitness functions investigating economic and emissions impact for a system intended to last for 20 years are mathematically shown in equation 2 and 3.

$$
F_{\$}=\sum_{\text {hour } i=1}^{8760} E_{p} \cdot E_{L}(i)+G_{p} \cdot T_{L}(i)+P(i)
$$

Where $E_{p}$ is the electric price, $E_{L}(i)$ is the electric load at hour $i, G p$ is the natural gas price, $T_{L}(i)$ is the heating and cooling load at hour $\mathrm{i}, \mathrm{P}(\mathrm{i})$ is the failure penalty at hour $\mathrm{i}$. The failure penalty refers to an arbitrary increase in the function value (thus reducing its favorability) for failing to meet consumer demand. Since the genetic algorithm is designed to minimize the objective functions, undesirable outcomes (such as increased costs and emissions) are given a positive value while desirable ones are given a negative one.

$$
F_{\mathrm{CO} 2}=\sum_{\text {hour } i=1}^{8760} \mathrm{CHPe}_{\mathrm{CO} 2} \cdot E_{L}(i)+\mathrm{CHPg}_{\mathrm{CO} 2} \cdot T_{L}(i)-G_{\mathrm{CO} 2} \cdot E_{L}(i)
$$

Where $\mathrm{G}_{\mathrm{CO} 2}$ is the grid emission intensity, $\mathrm{CHPe}_{\mathrm{CO} 2}$ and $\mathrm{CHPg}_{\mathrm{CO} 2}$ is the equivalent emissions intensity for the electricity generated by the CHP and natural gas equivalent emissions intensities respectively.

The technologies are selected from databases of PV, CHP, and battery technologies that include each technology's various technical characteristics and are populated from a combination of literature review and product specification sheets. For the purposes of this research, PVTOM selected from a total of four internal combustion micro-CHP technologies, ten photovoltaic panels, and seven battery types. A typical optimization simulates close to 3,000 different configurations before converging to a solution. Each simulation relies on an 
Preprint of: A.H. Nosrat, L.G. Swan, J.M. Pearce, Improved Performance of Hybrid Photovoltaic-Trigeneration Systems Over Photovoltaic-Cogen Systems Including Effects of Battery Storage, Energy 49, pp. 366-374 (2013). http://dx.doi.org/10.1016/j.energy.2012.11.005

electric and load following strategy documented in Nosrat and Pearce [30].

In order to provide a comparison between hybrid PV-cogen and PV-trigen systems, PVTOM was applied to three different Canadian case studies that included space cooling requirements throughout the year: 1) a single detached (SD) house in Kingston, Ontario; 2) a double/row (DR) house in Kingston, Ontario; and 3) a SD house in Vancouver, British Columbia. Kingston was selected due to the author's university location and Vancouver was selected to study a different climate within Canada. A synopsis of the end-user requirements are shown for each house in Table 1.

Table 1. End-use energy requirements in selected Canadian residences

\begin{tabular}{rcccccccc}
\hline & \multicolumn{4}{c}{ Annual End-Use Demand $(\mathbf{k W h})$} & \multicolumn{4}{c}{ Peak Hourly Load (kW) } \\
\hline House Sample & AL & DHW & SH & SC & AL & DHW & SH & SC \\
Kingston SD & 7447 & 4114 & 9509 & 1609 & 5.1 & 11.2 & 6.5 & 3.7 \\
Kingston DR & 8717 & 3366 & 8750 & 2210 & 7.4 & 9.2 & 6.6 & 3.8 \\
Vancouver SD & 16041 & 2714 & 7683 & 8648 & 8.9 & 7.4 & 6.2 & 9.6 \\
\hline
\end{tabular}

\section{Results and Discussion}

All three optimization runs converged in fewer than 25 iterations, or roughly 2,635 individual simulations (each iteration requires 105 simulations based on pre-defined GA parameters). Each simulation requires approximately 6 seconds for completion on $1.6 \mathrm{GHz}$ processor. Therefore, 20-25 iterations would take 3.5-4.4 hours. A summary of the optimized system configurations based on PVTOM for the three case studies are shown in Table 2. The energy utilization efficiency results for both the PV-cogen and PV-trigen simulations are shown in Table 3. These may be compared to a theoretical upper energy utilization efficiency of $85 \%$ for stand-alone CHP systems [14]. The case studies demonstrate that hybridization of PV and trigeneration can yield energy utilization efficiencies higher than the theoretical stand-alone limit. Energy utilization, as defined in equation (1), is the ratio of utilized energy to the higher heating value of the consumed fuel by the system. Arguably, the PV and battery components do not consume any artificially extracted fuels during operation, hence driving up the system's energy utilization factor to even above $100 \%$.

Based on the results, there seems to be higher savings when moving to the trigen vs. cogen system for the Vancouver SD house when compared to the two Kingston houses. This can be primarily attributed to the relatively higher space cooling requirement that is capable of utilizing much of the waste heat produced in the warmer periods of the year. Similarly in Table 3, it can be concluded that energy efficiency significantly increases when there is a considerable space cooling demand for the end-user. For both of the Kingston houses, the energy efficiency has been subject to a significant deterioration as the CHP unit has been forced to operate at hours that did not require space cooling production.

The PV-trigen systems also demonstrate superior performance in other metrics. In PVTOM, the demandsupply match index represents the timely production of energy to meet demand, where lower values indicate better matches. Mathematically, this is expressed as:

$$
L S M_{O S}=\sum_{i=1}^{8760} \frac{\operatorname{Excess}_{\theta l}(i)+\operatorname{Excess}_{t h}(i)+\text { Fail }_{\theta l}(i)+\text { Fail }_{t h}(i)}{P_{A C, \text { load }}(i)+Q_{D H W}(i)+Q_{S H}(i)+Q_{S C}(i)}
$$

where Excess $_{\text {el }}$ (i) and Excess $_{\mathrm{th}}$ (i) are the amount of excess electric and thermal energy produced at a given hour

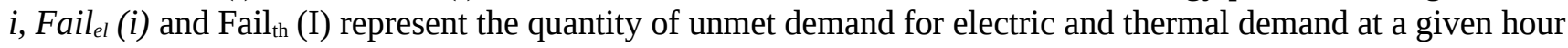
$i$, and the denominator is the sum of the four end-use energy requirements at a given hour $i$.

The normalized power supply index is the ratio of total annual produced electrical energy to the 
Preprint of: A.H. Nosrat, L.G. Swan, J.M. Pearce, Improved Performance of Hybrid Photovoltaic-Trigeneration Systems Over Photovoltaic-Cogen Systems Including Effects of Battery Storage, Energy 49, pp. 366-374 (2013). http://dx.doi.org/10.1016/j.energy.2012.11.005

combined system capacity of the CHP and photovoltaic units. Higher values indicate more energy produced per unit power. These two indices are shown in Table 4 for the three simulated houses. The hybrid PV-trigen systems show consistently higher normalized power indices than the PV-cogen. This means that the PV-trigen systems provide a higher amount of energy per unit power than PV-cogen systems. Furthermore, the PV-trigen systems have lower load-supply match indices, further demonstrating improved performance due to more effective utilization of produced electric and thermal energy.

Table 2. Configuration of optimized hybrid PV-trigen system for case studies. All systems each utilized a single CHP system.

\begin{tabular}{|c|c|c|c|c|c|c|}
\hline & $\begin{array}{c}\text { Parallel } \\
\text { PV }\end{array}$ & $\begin{array}{l}\text { Parallel } \\
\text { Batteries }\end{array}$ & $\begin{array}{l}\text { Batteries } \\
\text { in Series }\end{array}$ & $\begin{array}{l}\text { CHP } \\
\text { Technology }\end{array}$ & $\begin{array}{l}\text { PV Technology at } \\
2^{\circ} \mathrm{C} / 1000 \mathrm{~W} / \mathrm{m}^{2}\end{array}$ & $\begin{array}{l}\text { Battery } \\
\text { Technology }\end{array}$ \\
\hline $\begin{array}{l}\text { Kingston } \\
\text { SD }\end{array}$ & 6 & 6 & 8 & $\begin{array}{l}1 \mathrm{kWe}, 3 \mathrm{kWth} \\
\text { Honda }\end{array}$ & $\begin{array}{l}\text { BP Solar BP380 } \\
\text { (380 Nom W) }\end{array}$ & $\begin{array}{l}\text { Trojan L16P } \\
\text { (360 Ah) }\end{array}$ \\
\hline $\begin{array}{l}\text { Kingston } \\
\text { DR }\end{array}$ & 2 & 6 & 8 & $\begin{array}{l}1 \text { kWe, } 3 \text { kWth } \\
\text { Honda }\end{array}$ & $\begin{array}{l}\text { Schott EFG } 310 \\
(310 \text { Nom W) }\end{array}$ & $\begin{array}{l}\text { Trojan T-105 } \\
\text { (225 Ah) }\end{array}$ \\
\hline Vancouver & 3 & 9 & 8 & $\begin{array}{l}1 \text { kWe, } 3 \text { kWth } \\
\text { Honda }\end{array}$ & $\begin{array}{l}\text { Schott EFG } 310 \\
(310 \text { Nom W) }\end{array}$ & $\begin{array}{l}\text { Trojan T-105 } \\
\text { (225 Ah) }\end{array}$ \\
\hline
\end{tabular}

Table 3. Percentage of Utilized Energy to Consumed Fuel

\section{CHP Energy Utilization \\ Efficiency for PV-Trigen}

\section{CCHP Energy Utilization \\ Efficiency PV-Cogen}

\begin{tabular}{rrr}
\hline Kingston SD & $91 \%$ & $98 \%$ \\
Kingston DR & $85 \%$ & $94 \%$ \\
Vancouver SD & $78 \%$ & $105 \%$ \\
\hline
\end{tabular}

Table 4. System Indicator Comparison for PV-cogeneration and PV-trigeneration Systems

\begin{tabular}{rcccc}
\hline & $\begin{array}{c}\text { CHP Normalized } \\
\text { Power Index for } \\
\text { Overall System } \\
(\mathbf{k W h} / \mathbf{k W})\end{array}$ & $\begin{array}{c}\text { CCHP Normalized } \\
\text { Power Index for } \\
\text { Overall System } \\
(\mathbf{k W h} / \mathbf{k W})\end{array}$ & $\begin{array}{c}\text { CHP Load- } \\
\text { Supply } \\
\text { Match Index }\end{array}$ & $\begin{array}{c}\text { CCHP Load- } \\
\text { Supply Match } \\
\text { Index }\end{array}$ \\
\hline Kingston SD & 877 & 903 & 1.63 & 1.53 \\
Kingston DR & 583 & 617 & 1.6 & 1.45 \\
Vancouver SD & 729 & 792 & 1.71 & 1.37 \\
\hline
\end{tabular}

Accordingly, improved energy utilization factor is expected to lead to improved emissions performance. Figure 6 is an illustration of the emission intensity for four different commercial residential scale cogeneration technologies and centralized power generation facilities. It is important to note that the centralized power generation facilities do not provide thermal energy required for SH and DHW end-use requirement. Average central power plant emission intensities were obtained from average plant efficiencies for the each technology, energy content, and rated emission intensities per unit volume or weight [31]. The average emission intensities 
Preprint of: A.H. Nosrat, L.G. Swan, J.M. Pearce, Improved Performance of Hybrid Photovoltaic-Trigeneration Systems Over Photovoltaic-Cogen Systems Including Effects of Battery Storage, Energy 49, pp. 366-374 (2013). http://dx.doi.org/10.1016/j.energy.2012.11.005

were calculated from weighted emission outputs and energy content for common electric and residential thermal fuel sources used in Canada that was obtained from the Environment Canada [32]. Sample centralized power plants were also analyzed to demonstrate the emission intensities of current technologies pertaining to energy production in non-Canadian contexts [33].

In Canada, natural gas and light fuel oil are considered to be the two primary sources of heat energy for residential users and were considered as possible energy consuming scenarios that would in turn affect the net GHG emissions. This is particularly important as fuel used by centralized power plants are solely used for electricity and fuel used by residential heating technologies is used for heating applications. Therefore, there is no overlapping energy use and therefore emission output between these two modes of production. Figure 6 represents the emission intensity of the optimized commercial technologies for the different representative load profiles by calculating the ratio of the net GHG emission output of the different systems to the sum of the electric and thermal loads. In order to determine the emission intensity of PV-CHP systems, the SC load was not included.

\section{Figure 6.}

It is clear from Figure 6, the optimized hybrid systems have significantly improved GHG emissions in comparison to their non-hybrid cogeneration counterparts as well as centralized power plant technologies. In profiles that required space cooling, there is a general improvement in the GHG emission intensity of hybrid trigeneration systems as opposed to the cogeneration type. Similar to energy utilization efficiency, PV-trigen systems provide superior performance in emission intensity for the Kingston SD and DR cases in a small amount, while in the Vancouver SD case study with more significant cooling loads there was a large improvement in the emission intensity profile with the addition of absorption chiller cooling equipment. It should be noted that despite the higher emission intensity of single CHP systems, the inclusion of photovoltaic technology has significantly contributed to the reduction of GHG emissions for residential applications.

The results demonstrated in Figure 6 clearly illustrate the advantages of implementing PV-trigen technologies as a means in reducing emission intensities with different Canadian regions by transitioning away from centralized power plant systems, particularly coal. The average PV-trigen system has shown to reduce emission intensities by as much as $90 \%$ when compared to centralized coal power plants and $50 \%$ for an average Canadian natural gas power plant.

As both the technologies of trigeneration and PV mature the economic feasibility of these systems improve. In the PV case in particular, recent scaling and technical improvements have reduced the levelized cost of electricity to a point where PV-generated electricity is competitive with conventional centralized sources [34]. Similarly with new technology the cost of natural gas has also declined significantly as the supply has increased with new technologies [35]. These price reductions in the system components and generation cost of electricity indicate that the symbiotic PV-trigeneration system will be viable in the near term at geographic regions throughout the world. The application of PV trigeneration systems should be viewed in the context of limited practical experience in the implementation of this technology. The purpose of PVTOM is to encapsulate the potential of integrating multiple technologies that will have interactive effects resulting in increased efficiency. It is expected that the implementation of these technologies are subject to complications and anomalies that are not captured in the model. What can be inferred, however, is that there is near certain potential in developing these systems in practice. In a market with chronically high and volatile energy prices, innovation in forming integrated energy solutions brings both economic and environmental benefits.

Practically, there may be additional benefits if these symbiotic systems were investigated for communal applications. It is expected that this may bring additional efficiencies due to larger system sizes (and thus improved exergy efficiency), bulk purchasing and consumer profiles. While this application has not been investigated within the scope of this study, it is suggested for future work. Another component of the PVTOM model, which could be further refined to guide the viability and durability of the system pertains to the charge and discharge cycle of the battery bank. Upper and lower charging limits should be investigated to be 
Preprint of: A.H. Nosrat, L.G. Swan, J.M. Pearce, Improved Performance of Hybrid Photovoltaic-Trigeneration Systems Over Photovoltaic-Cogen Systems Including Effects of Battery Storage, Energy 49, pp. 366-374 (2013). http://dx.doi.org/10.1016/j.energy.2012.11.005

incorporated as a decision parameter in PVTOM optimization. This analysis will reveal challenges pertaining to power management that is often present in electric storage technologies and again help accelerate the deployment of this promising technology.

\section{Conclusions}

This paper demonstrated the utility of the PV-Trigeneration Optimization Model (PVTOM) for evaluating complex PV-trigen systems in a way that is applicable to any geographic location. In order to provide a comparison between the energy utilization efficiency of two hybrid energy systems, PV-cogen and PV-trigen, for select Canadian residential end-users this article coupled the PVTOM with the Canadian Hybrid Residential End-Use Energy and Emissions Model (CHREM). Based on the results of these simulations, it was found that PV-trigen systems have superior energy utilization efficiency when compared to PV-cogen, in regions that experience significant cooling loads. PV-trigen systems have also demonstrated better greenhouse gas emission performances when compared to PV-cogen systems. In addition to comparing the two types of hybrid waste heat capture and solar electric systems these results provided further support that such systems are a technically viable method of reducing greenhouse gas emissions throughout most regions. Both the PV-trigen and PV-cogen systems have demonstrated substantial greenhouse gas emissions reduction potential (50-90\%) when compared to the current combination of centralized power plants and household heating technologies found throughout Canada.

\section{Acknowledgements}

The authors acknowledge the Natural Sciences and Engineering Research Council of Canada for support of this work.

\section{References}

1. Solomon S, Qin D, Manning M, Chen Z, Marquis M, Averyt KB, Tignor M, Miller HL. Contribution of Working Group I to the Fourth Assessment Report of the Intergovernmental Panel on Climate Change. Cambridge, United Kingdom and New York, NY, USA: Cambridge University Press; 2007.

2. Hansen J, Sato M, Kharecha P, Beerling D, Berner R, Masson-Delmotte V, Pagani M, Raymo M, Royer DL, Zachos JC. Target atmospheric $\mathrm{CO}_{2}$ : where should humanity aim?,The Open Atmospheric Science Journal 2008; 2.

3. International Energy Agency. Key World Energy Statistics 2010. Paris, France: International Energy Agency; 2010.

4. National Petroleum Council. Topic Paper \#4 Electricity Generation Efficiency. National Petroleum Council Global Oil and Gas Study, 2007. Available at: http://www.npc.org/Study_Topic_Papers/4-DTGElectricEfficiency.pdf

5. Kenny R, Law C, Pearce JM. Towards Real Energy Economics: Energy Policy Driven by Life-Cycle Carbon Emission. Energy Policy 2010; 38:1969-1978.

6. Sirchis J, Combined Production of Heat and Power (Cogeneration). London and New York: Elsevier Applied Science; 2005.

7. Srikhirin P, Aphornratana S, Chungpaibulpatana S. A review of absorption refrigeration technologies. Renew and sustain energy reviews 2001; 5(4): 343-372.

8. Hernandez-santoyo J. Trigeneration: an alternative for energy savings. Applied Energy 2003, 76(1): 219-227.

9. Chicco G, Mancarella P. From Cogeneration to Trigeneration: Profitable Alternatives in a Competitive

Market. IEEE Transactions on Energy Conversion 2006; 21(1): 265-272.

10. Pearce J. Photovoltaics - A Path to Sustainable Futures. Futures 2002; 34(7): 663-674. 
Preprint of: A.H. Nosrat, L.G. Swan, J.M. Pearce, Improved Performance of Hybrid Photovoltaic-Trigeneration Systems Over Photovoltaic-Cogen Systems Including Effects of Battery Storage, Energy 49, pp. 366-374 (2013). http://dx.doi.org/10.1016/j.energy.2012.11.005

11. Pernick R, Wilder C. Utility Solar Assessment Study Reaching Ten Percent Solar by 2025, Clean Edge, Inc. and Co-op America Foundation, 2008: 1-76.

12. Sims R. Carbon emission and mitigation cost comparisons between fossil fuel, nuclear and renewable energy resources for electricity generation. Energy Policy 2003; 31(13): 1315-1326.

13. Kirkegaard JF, Hanemann T, Weischer L, Miller M. Toward a Sunny Future? Global Integration in the Solar PV Industry. World Resources Institute Working Paper Series, 2010:1- 66.

14. Pearce JM. Expanding Photovoltaic Penetration with Residential Distributed Generation from Hybrid Solar Photovoltaic + Combined Heat and Power Systems. Energy 2009; 34: 1947-1954.

15. Derewonko P, Pearce JM. Optimizing Design of Household Scale Hybrid Solar Photovoltaic + Combined Heat and Power Systems for Ontario. 34 ${ }^{\text {th }}$ IEEE Photovoltaic Specialists Conference 2009:1274-1279.

16. Mostofi M, Nosrat AH, Pearce JM. Institutional scale operational symbiosis of photovoltaic and cogeneration energy systems. Int. J. Environ. Sci. 2011; 8(1): 31-44.

17. Swan LG, Ugursal VI, Beausoleil-Morrison I. A database of house descriptions representative of the Canadian housing stock for coupling to building energy performance simulation. J. of Building Performance Simulation 2009; 2(2): 75-84.

18. Swan LG, Ugursal VI, Beausoleil-Morrison I. Occupant related household energy consumption in Canada: Estimation using a bottom-up neural-network technique. Energy and Buildings 2011;43(2-3): 326-337.

19. Swan LG, Ugursal VI, Beausoleil-Morrison I (2011a). Hybrid Residential End-Use Energy and GHG Emissions Model - Development and Verification for Canada. Journal of Building Performance Simulation. In-press. DOI:10.1080/19401493.2011.594906

20. Petchers N. Combined heating, cooling \& power handbook technologies \& applications: an integrated approach to energy resource optimization. Lilburn GA ;New York: Fairmont Press; Distributed by Marcel Dekker, 2003.

21. Renewable Energy Policy network for the $21^{\text {st }}$ century. Renewables 2007 Global Status Report 2008:1-54.

22. Doty GN, McCree DL, Doty JM, Doty FD. Deployment Prospects for Proposed Sustainable Energy Alternatives in 2020, ASME Conf. Proc. 2010; 171(1): 171-182.

23. Price S, Margolis R. Solar technologies market report, Energy Efficiency \& Renewable Energy, US Department of Energy, January 2010:1-131.

24. Branker K, Pearce JM. Financial Return for Government Support of Large-Scale Thin-Film Solar Photovoltaic Manufacturing in Canada. Energy Policy 2010;38:4291-4303.

25. Messenger R. Photovoltaic Systems Engineering, Second Edition. London:CRC Press; 2003.

26. Jimenez T. Hybrid Design Handbook. EDRC, NREL; 1998.

29. Nosrat AH. Simulation and Optimization of Hybrid Photovoltaic (PV) and Combined Cooling, Heating, and Power Systems. Master's Thesis Dissertation, Kingston, ON:Queen's University; 2010.

30. Nosrat AH, Pearce JM. Dispatch Strategy and Model for Hybrid Photovoltaic and Combined Heating, Cooling, and Power Systems. Applied Energy 2011; 88:3270-3276.

31. Farhat AAM, Ugursal VI. Greenhouse gas emission intensity factors for marginal electricity generation in Canada. Int'l J of Energy Research 2010;34(15): 1309-1327.

32. Environment Canada. 1990-2005: Greenhouse Gas Sources and Sinks in Canada. National Inventory Report. Ottawa: Environment Canada; 2007.

33. Chungsangunsit T, Gheewala SH, Patumsawad S. Emission Assessment of Rice Husk Combustion for Power Production. World Acad. of Sci.: Eng. and Tech. 2009;53:1070-1075.

34. Branker K, Pathak MJM, Pearce JM. A Review of Solar Photovoltaic Levelized Cost of Electricity. Renewable \& Sustainable Energy Reviews 2011; 15:4470-4482.

35. Palmer K, Burtraw D, Woerman M, Beasley B. The Effect of Natural Gas Supply on Retail Electricity Prices. Resources for the Future, Issue Brief 12-05. August 2012. 
Preprint of: A.H. Nosrat, L.G. Swan, J.M. Pearce, Improved Performance of Hybrid Photovoltaic-Trigeneration Systems Over Photovoltaic-Cogen Systems Including Effects of Battery Storage, Energy 49, pp. 366-374 (2013). http://dx.doi.org/10.1016/j.energy.2012.11.005

\section{Figure Captions}

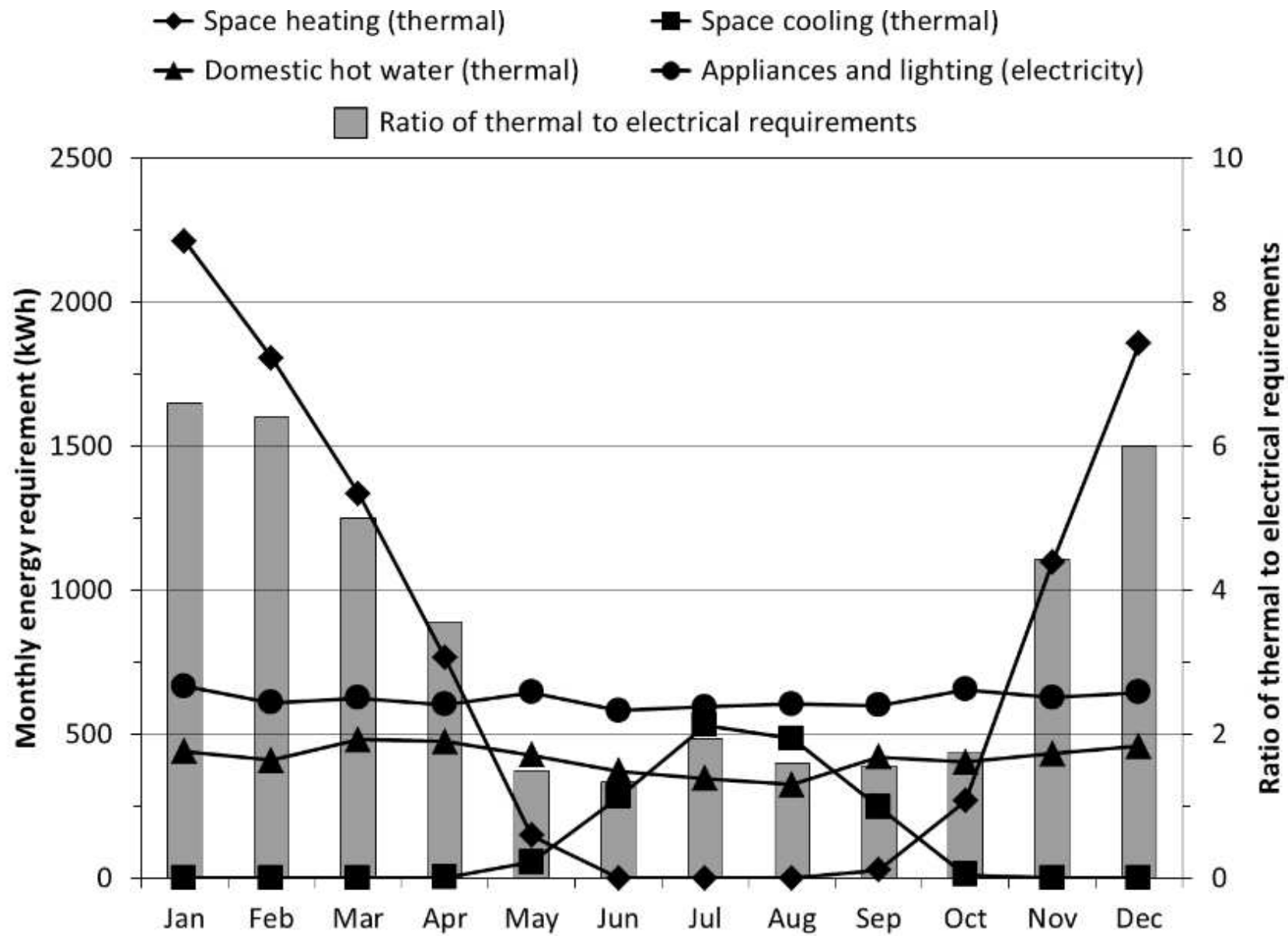

Figure 1: Comparison of the thermal and electrical requirements of a house located in Kingston, Ontario, Canada. 
Preprint of: A.H. Nosrat, L.G. Swan, J.M. Pearce, Improved Performance of Hybrid Photovoltaic-Trigeneration Systems Over Photovoltaic-Cogen Systems Including Effects of Battery Storage, Energy 49, pp. 366-374 (2013). http://dx.doi.org/10.1016/j.energy.2012.11.005


July 12 in hours

Figure 2: Direct and diffuse solar radiation levels of Kingston, Ontario, Canada shown at (a) annual and (b) daily (July 12) levels. 
Preprint of: A.H. Nosrat, L.G. Swan, J.M. Pearce, Improved Performance of Hybrid Photovoltaic-Trigeneration Systems Over Photovoltaic-Cogen Systems Including Effects of Battery Storage, Energy 49, pp. 366-374 (2013). http://dx.doi.org/10.1016/j.energy.2012.11.005

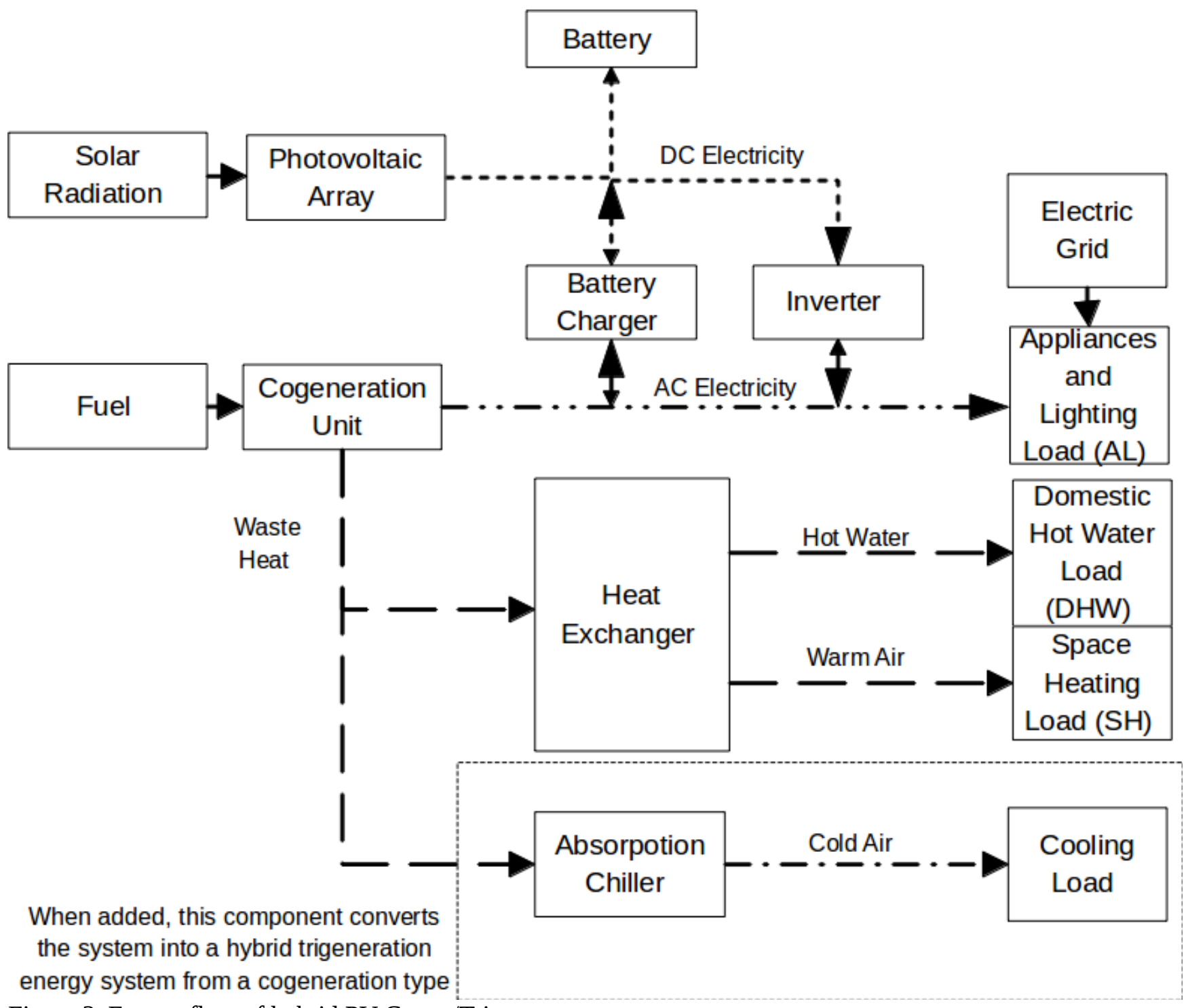

Figure 3. Energy flow of hybrid PV-Cogen/Trigen system. 
Preprint of: A.H. Nosrat, L.G. Swan, J.M. Pearce, Improved Performance of Hybrid Photovoltaic-Trigeneration Systems Over Photovoltaic-Cogen Systems Including Effects of Battery Storage, Energy 49, pp. 366-374 (2013). http://dx.doi.org/10.1016/j.energy.2012.11.005

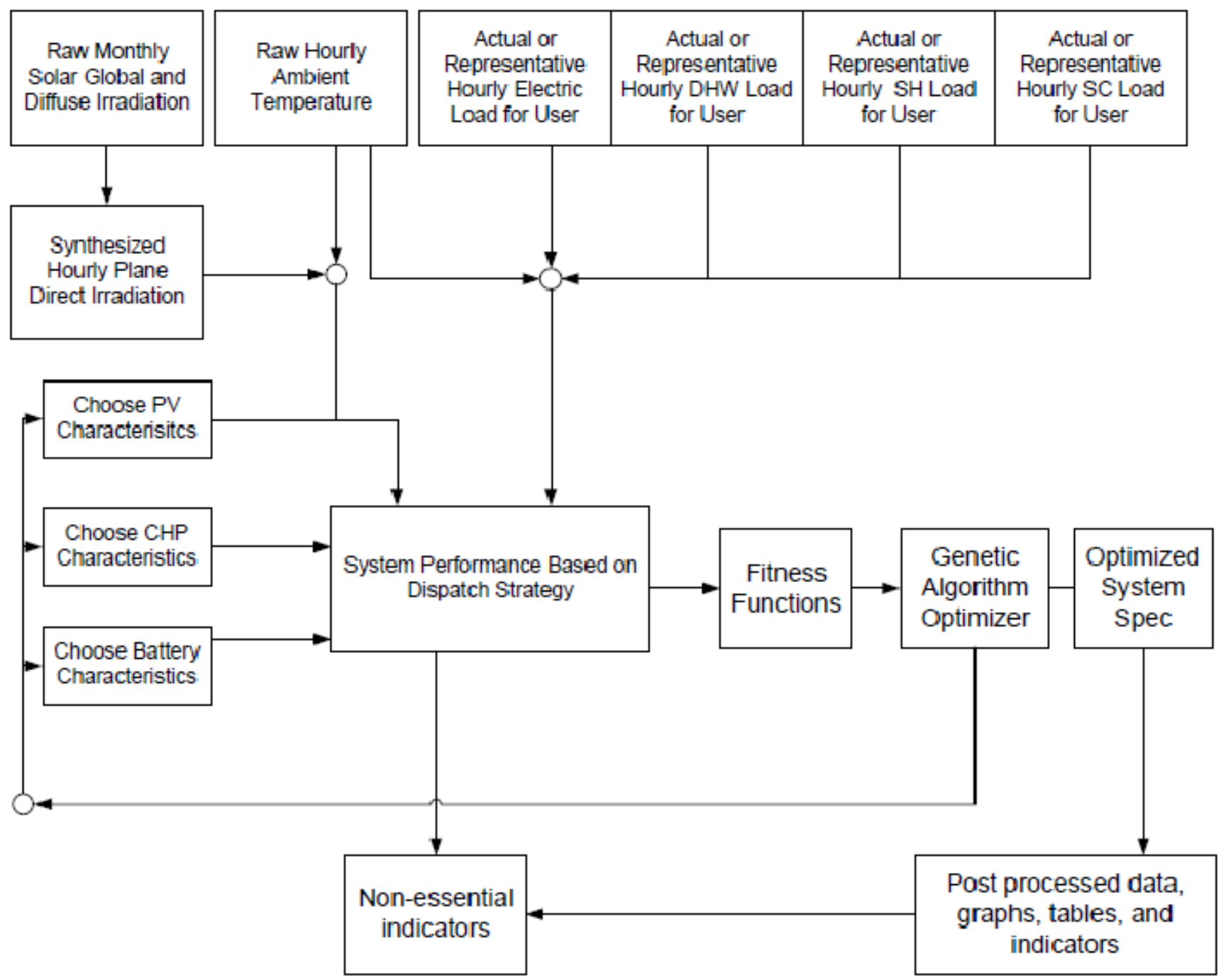

Figure 4. PVTOM optimization routine. 
Preprint of: A.H. Nosrat, L.G. Swan, J.M. Pearce, Improved Performance of Hybrid Photovoltaic-Trigeneration Systems Over Photovoltaic-Cogen Systems Including Effects of Battery Storage, Energy 49, pp. 366-374 (2013). http://dx.doi.org/10.1016/j.energy.2012.11.005

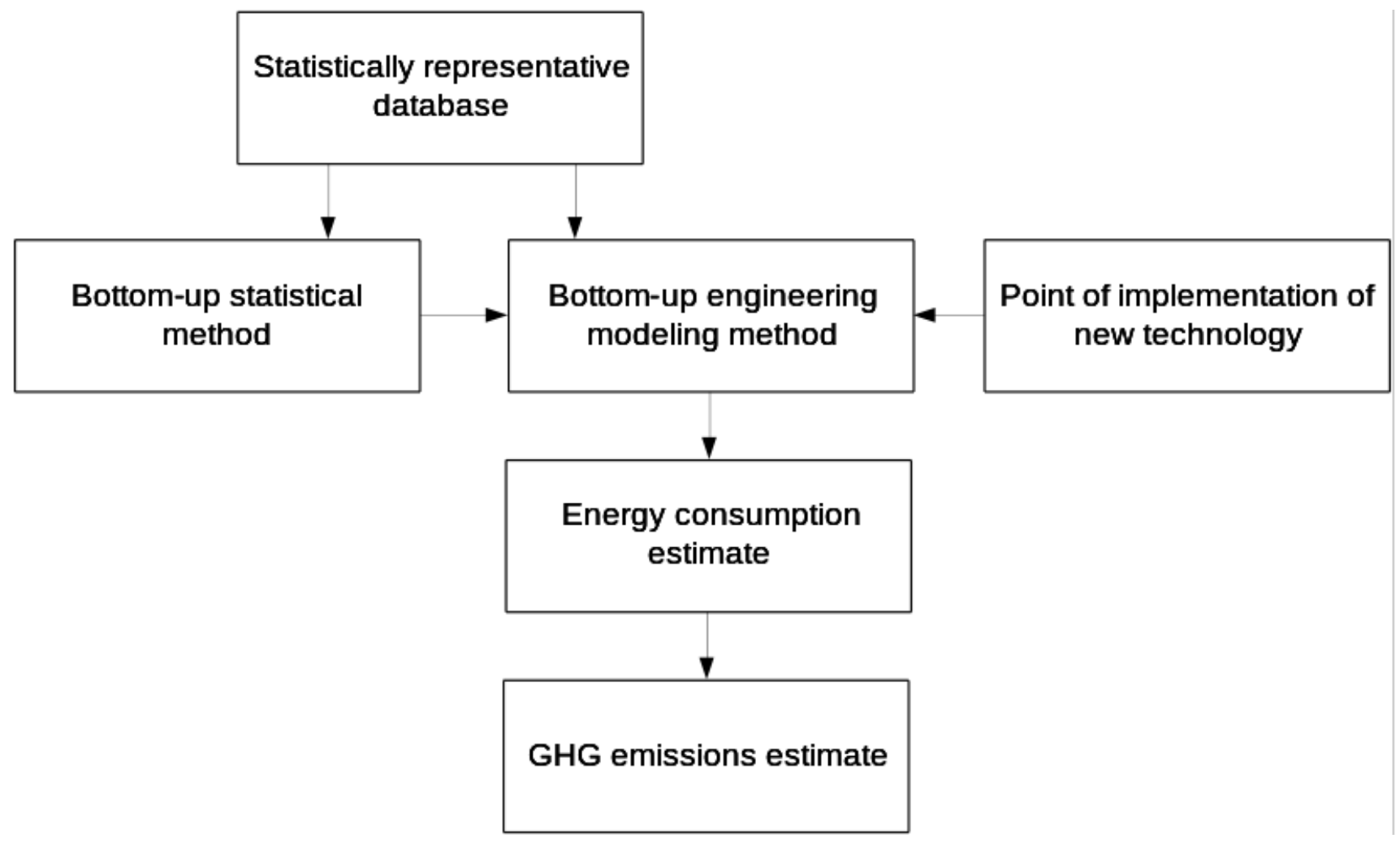

Figure 5. Flowchart of the CHREM model. 
Preprint of: A.H. Nosrat, L.G. Swan, J.M. Pearce, Improved Performance of Hybrid Photovoltaic-Trigeneration Systems Over Photovoltaic-Cogen Systems Including Effects of Battery Storage, Energy 49, pp. 366-374 (2013). http://dx.doi.org/10.1016/j.energy.2012.11.005

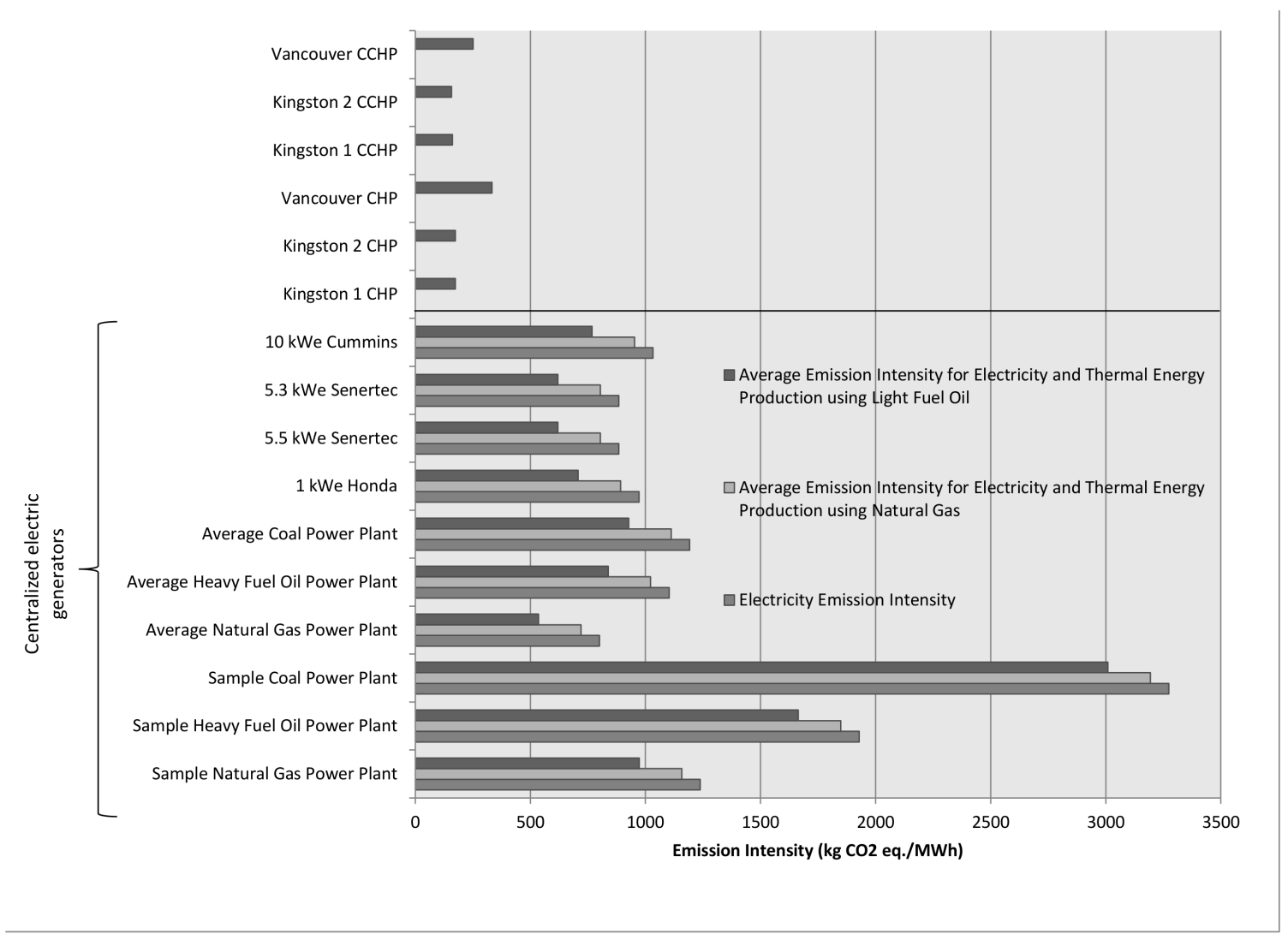

Figure 6. Emission intensity comparison for PV-CHP, PV-CCHP, and centralized systems for select case studies to meet all end-uses (both thermal and electrical). The average emission intensities are for on site electrical and thermal energy production. 